\title{
A PERFORMATIVIDADE NAS POLÍTICAS DE CURRÍCULO: O CASO DO ENEM'
}

\author{
Alice Casimiro Lopes* \\ Silvia Braña López**
}

RESUMO: Este artigo articula os efeitos da globalização com as políticas de currículo e de avaliação. Defendemos, com base em Stephen Ball, a compreensão das políticas de currículo como produção de sentidos e significados para as decisões curriculares em um ciclo contínuo de produção de políticas. Entendemos que uma das dimensões dessas políticas de currículo é a produção de uma cultura da performatividade, expressa, entre outras ações, pelo Exame Nacional do Ensino Médio (ENEM). Pela investigação de documentos relativos ao ENEM, identificamos que o foco desse exame é a formação do indivíduo onicompetente para a eficiência social do sistema, porém, diferentemente de outras épocas, centrado na autorregulação de suas performances. Além disso, consideramos que a cultura da performatividade influencia dimensões locais da avaliação, com diferentes extensões e modos de avaliar, não necessariamente associados às mesmas finalidades dos exames centralizados.

Palavras-chave: Avaliação; ENEM; Performatividade; Política de Currículo.

\section{THE PERFORMATIVITY IN THE CURRICULUM POLICY: THE CASE OF ENEM}

ABSTRACT: This paper articulates globalization effects with curriculum policy and evaluation. We argue, based on Stephen Ball, that curriculum policy is a production of meanings to curricular decisions in a continuous policy cycle. We also argue that one of the dimensions of this curriculum policy is the production of the performance-oriented tivity culture. This culture is expressed, for example, in the National Exam of to High School (Exame Nacional do Ensino Médio - ENEM). We have identified in the ENEM's documents that the focus of this exam is the development formation of an omnicompetent individual to the system's social efficiency. However, this focus is differs ent at from other times, as because it is centered in the performances self-regulation. Furthermore, the improvement of a performance-oriented tivity culture influences local dimensions of evaluation, with different extensions and ways of evaluation. These local dimensions of evaluation are not necessarily associated to the same centralized exams' aims.

Keywords: Curriculum Policy; ENEM; Evaluation; Performativity.

\footnotetext{
* Professora do Programa de Pós-Graduação em Educação - PROPED - da Universidade do Estado do Rio de Janeiro (UERJ). E-mail: alicecasimirolopes@gmail.com

* Mestre em Educação pela Universidade do Estado do Rio de Janeiro (UERJ); Doutoranda no Instituto Fernandes Figueira da Fundação Oswaldo Cruz (FIOCRUZ).
} 


\section{Introdução}

As mudanças no paradigma educacional produzidas nas últimas décadas têm sido, de forma geral, associadas aos efeitos da globalização. Um desses efeitos pode ser identificado na capilarização da cultura da performatividade nas políticas de currículo. A compreensão restrita do currículo como conteúdos a serem validados por sistemas de avaliação centralizados nos resultados e os consequentes rankings de escolas e de alunos são apenas algumas das evidências públicas dos discursos produzidos por essa cultura.

$\mathrm{Na}$ medida em que defendemos a compreensão das políticas de currículo como produção de sentidos e significados para as decisões curriculares em múltiplos contextos, de maneira a constituir um ciclo contínuo de produção de políticas (BALL, 1994), não trabalhamos com o entendimento de que essa cultura da performatividade seja um discurso produzido exclusivamente pelo Estado ou pelas agências governamentais. Uma característica importante da abordagem do ciclo de políticas é sua crítica a essa centralidade do Estado (LOPES, 2006; MAINARDES, 2007), passando pelo entendimento de que toda política expressa uma negociação de sentidos curriculares ambivalentes. Buscamos, assim, nos diferenciar de perspectivas que analisam exames centralizados nesse enfoque (ZANCHET, 2002), por entendermos que, além dessas influências, reinterpretações globais e locais se inserem nos discursos políticos de currículo. Por essas reinterpretações, o discurso se torna muito mais matizado e capaz de produzir efeitos variados.

É nessa perspectiva que apresentamos a análise de documentos relativos ao Exame Nacional do Ensino Médio (ENEM), investigando os princípios que apontam para a construção desse discurso favorável à cultura da performatividade. Defendemos que o foco desse exame é a formação do indivíduo onicompetente para a eficiência social do sistema de ensino e, consequentemente, do sistema social. Salientamos, porém, que, diferentemente de outras épocas, ele é centrado na autorregulação das performances do indivíduo. Defendemos, ainda, que essa autorregulação proposta produz efeitos diferentes, com finalidades distintas, em múltiplos contextos.

Ao considerarmos que o ENEM se insere no conjunto de ações que expressam e constituem uma cultura da performatividade nas 
políticas de currículo, não pretendemos identificá-lo como a expressão máxima ou exclusiva dessa cultura, mas como exemplo de reinterpretação local, com efeitos particulares, sintonizada com essa cultura global mais ampla. Tampouco consideramos que as conclusões aqui estabelecidas para o Enem podem ser transpostas para outros discursos associados à defesa de uma cultura da performatividade, uma vez que não se trata de uma homogeneidade de sentidos que se impõem indistintamente, independentemente das lutas políticas locais e das finalidades postas em jogo. Mas ainda assim consideramos que esta análise particular pode contribuir para outras interpretações de discursos correlatos, não apenas marcando possíveis aproximações, mas distanciamentos significativos.

Neste artigo, de forma a desenvolver os argumentos em defesa de nossas conclusões de análise, primeiramente esboçamos, com base em Friederich Jameson e Bob Lingard, o cenário constituído a partir do fenômeno da globalização. Para tal, focalizamos aspectos relacionados às mudanças no mundo do trabalho e sua relação com as políticas educacionais globais. Seguimos com a discussão proposta por Stuart Hall a respeito da centralidade adquirida pela cultura na atualidade e o uso desta como forma de regulação social, associando-a às discussões da performatividade, com Stephen Ball e Michel Foucault. Apresentamos, por fim, pela análise dos documentos, o discurso que toma por base a performatividade como forma de pensar globalmente o indivíduo onicompetente, bem como sua influência em dimensões locais das avaliações, com diferentes extensões e modos de avaliar.

\section{0 cenário das políticas: o mundo globalizado}

A complexidade do processo de globalização reside no fato de que não introduz somente mudanças quantitativas na produção e no trabalho, mas também mudanças qualitativas. Jameson (2001) nos convida a deslocar o foco de discussão em torno da globalização da definição teórica de um conceito para a análise dos efeitos da globalização. Propõe, então, cinco níveis distintos da globalização: o tecnológico, o político, o cultural, o econômico e o social, "exatamente nessa ordem” (p. 17). O nível tecnológico refere-se a uma nova tecnologia que não se restringe 
somente ao campo das comunicações, mas também ao da produção e da comercialização de produtos (circulação de mercadorias e serviços). Quanto ao efeito político, o foco está na questão da nova configuração dos Estados-nação, com fronteiras não tão definidas. Em relação à cultura, Jameson considera relevante refletir sobre a tensão entre as culturas locais e os esforços de estandardização delas por uma cultura que se mundializa, partindo desses efeitos culturais os efeitos econômicos da globalização. Jameson identifica ainda a estetização das mercadorias como o fenômeno cultural que atravessa o atual processo de produção, capazes de tornar cada vez mais fluidos os limites entre cultura e economia. Concordamos com o autor que tal imbricação entre o cultural e o econômico traz profundas consequências para a esfera social, já que reconfigura toda uma agenda social que engendra as formas de ação política e torna também imbricadas a cultura e a política.

As consequências desse processo para a educação, por sua vez, são mais profundas do que a simples introdução de novas tecnologias e o fortalecimento de determinadas disciplinas em detrimento de outras, tais como: a inserção de novas linguagens da informática no currículo, o fortalecimento do ensino de ciências e matemática, a valorização da sociologia como suporte ao entendimento das relações transculturais, o domínio da linguagem, tanto oral quanto escrita, revelando a importância da comunicação em seus diversos sentidos. Expressando mudanças nas formas de trabalho no modo de produção capitalista, a centralidade da cultura e o reordenamento geopolítico-econômico em curso, surgem novas exigências em relação às competências e habilidades entendidas como necessárias ao trabalhador capaz de se inserir no mundo em mudança cada vez mais acelerada.

O projeto de formação desse trabalhador, não mais visto como qualificado para uma função, mas como mobilizador de competências algumas delas muito especializadas, vinculadas a determinadas funções transitórias -, facilita a articulação entre demandas construtivistas e demandas instrumentais. As demandas construtivistas, voltadas para competências complexas, centradas no processo de aprendizagem do aluno e com foco na construção do conhecimento, tornam-se agora compatíveis com as demandas instrumentais, voltadas para competências centradas no desempenho e para o controle do processo de ensinoaprendizagem, visando à eficiência da instrução (LOPES, 2008). Tal 
articulação também produz novas exigências para o professor capaz de garantir a formação de tal trabalhador. Como discute Dias (2006), a responsabilização individual do professor pelo desempenho do aluno e da escola, o foco na competitividade entre professores e a constituição de um perfil profissional ancorado nessas performances marcam a constituição da cultura da performatividade na formação de professores.

Em relação à atuação dos Estados-nação nesse cenário mundial, Ball (2004a, p. 1106) discute o surgimento de um acordo político do pósEstado da Providência, no qual observa "mudanças nos papéis do Estado, do capital, das instituições do setor público e dos cidadãos e nas suas relações entre si”. Esse autor inicialmente aponta para a modificação da qualidade das atividades do setor público. O Estado passa do estatuto de provedor para o de regulador, atuando como auditor na avaliação dos resultados alcançados pelos mercados internos. Uma segunda mudança por ele sinalizada refere-se à obtenção de lucro por meio de atividades de natureza social, quando as empresas rompem com as regulações do nãomercado e nele inserem seus princípios. A terceira mudança enfatizada por Ball diz respeito às instituições do setor público que são levadas a se inserirem em uma nova cultura de performances (desempenhos) competitivas, a partir da descentralização e dos incentivos a um novo perfil institucional. Por último, há a mudança que diz respeito aos cidadãos, os quais passam da posição de dependência em relação ao Estado do Bem-Estar Social para o papel de consumidores ativos. Associado a essas mudanças, não podemos deixar de considerar o fenômeno das trocas aceleradas de informação e de bens simbólicos, com grande intensificação dos intercâmbios culturais. A aceleração das desterritorializações e reterritorializações dos processos simbólicos torna os signos de identificação cultural, cada vez mais, não-fixos. Ainda segundo o autor (BALL, 1997), passamos a conviver com uma associação entre as velhas formas de gerencialismo, centradas no controle direto, mediante a ameaça de punições, e o novo gerencialismo, em que prevalecem processos de autorregulação: as pessoas são motivadas a assumir performances de qualidade e excelência, supostamente sem os mecanismos diretos de repressão anteriormente utilizados.

Esses intercâmbios culturais trazem outros desafios para $\mathrm{O}$ campo da pesquisa educacional, uma vez que fica mais evidente que a produção de políticas não é emanada exclusivamente dos centros globais 
de poder político, tais como organismos de representação internacional das nações, órgãos de financiamento de programas de desenvolvimento na esfera mundial, Estados-nação hegemônicos que "exportam" e disseminam diagnósticos e "soluções” políticas educacionais. Há que se considerar a tensão global-local como capaz de produzir novas configurações em um vigoroso processo de negociação e de recontextualização, ao que Appadurai (apud LINGARD, 2004) denomina "globalização vernacular".

Se, por um lado, podemos identificar a convergência de políticas no contexto de influência, tais como a formação por competências, a formação para o atendimento de demandas mercadológicas, a estruturação de processos de avaliação continuados, por outro, tal convergência não garante homogeneidade quando situada nos contextos de produção e de prática (BALL,1998; 2001). Tanto pela mediação dos Estados-nação e dos sujeitos e instituições atuantes em sua esfera, que articulam a produção de orientações oficiais, quanto pelas releituras no espaço escolar, na conversão das práticas globais em locais, os textos circulantes são reinterpretados, resultando na produção de discursos híbridos. Tal hibridismo é decorrente de um processo de recontextualização no qual discursos, ou mesmo fragmentos deles, são associados a discursos locais. Instaura-se uma negociação assimétrica entre esses discursos, incluindo ideias, documentos, experiências, práticas e pesquisas, constituídos localmente, que resultam em uma recriação híbrida no contexto da prática e no contexto de produção das orientações oficiais.

Nesse trânsito de sentidos e significados, constantemente recontextualizados nos múltiplos contextos, é que se dá a disseminação de uma política educacional global identificada como circulante nos países ocidentais pós-industriais. Essa política também é aqui considerada como formada por princípios locais que se globalizaram. Segundo Carter e O’Neil (apud BALL, 1998, p. 126), são cinco elementos principais que circulam com tais políticas: a) estreitamento da relação entre escolarização, produtividade e comercialização; b) busca da melhoria dos resultados escolares em termos de habilidades e competências exigidas pelo mercado de trabalho; c) estabelecimento de controle sobre os conteúdos curriculares e sua avaliação no âmbito das escolas, com foco no desempenho de professores e estudantes; d) busca da minimização dos custos educacionais para o governo; e, finalmente, e) incremento da 
participação e do envolvimento da comunidade, sobretudo por meio da participação dos responsáveis pelos estudantes e das exigências mercadológicas nos processos decisórios da instituição escolar.

Tais elementos engendram políticas de currículo que tentam instaurar processos de regulação por meio do que vem sendo denominado cultura da performatividade, a qual passamos a analisar.

\section{A Cultura da Performatividade como projeto de regulação da educação}

Tomando de empréstimo o conceito de cultura de Hall (1997) como conjunto de sistemas ou códigos de significados que dão sentido às nossas ações, podemos identificar as práticas sociais como práticas de significação e, como tais, não só definidoras dos significados dos objetos, mas também de sistemas de codificação, ordenação e regulação de modos de agir em sociedade. Nessa perspectiva, a cultura é definidora também das identidades sociais e da constituição dos sujeitos, na medida em que tais identidades e subjetividades derivam de processos discursivos, os quais possibilitam nos situarmos e nos movimentarmos na interioridade das definições fornecidas pelos discursos culturais. Com isso, ainda segundo Hall (1997, p. 32), “todas as práticas sociais, na medida em que sejam relevantes para o significado ou requeiram significado para funcionarem, têm uma dimensão 'cultural"'.

A essa perspectiva associamos a discussão de Foucault (1989) quando afirma que cada sociedade possui seu regime de verdade, a partir do qual produz efeitos coercitivos e regulamentados de poder. Cada sociedade estabelece uma "economia política" de verdade/poder pela qual certos tipos de discurso são acolhidos como verdadeiros e outros, não; na qual certos mecanismos e instâncias permitem distinguir os enunciados verdadeiros dos falsos, sancionando uns e outros; pela qual se constituem certas técnicas e procedimentos que são valorizados; na qual se define o estatuto daqueles que têm o encargo de dizer o que funciona como verdadeiro e válido. $\mathrm{O}$ poder e seu regime de verdade são disciplinares, atravessando toda a trama social. O poder "não destrói o indivíduo; ao contrário, ele o fabrica. $\mathrm{O}$ indivíduo não é o outro do poder, realidade exterior, que é por ele anulado; é um de seus mais importantes efeitos" (MACHADO, 1986, p. XX). 
Pela sintonia com esses enfoques, acreditamos na relevância das análises em torno dos sentidos e significados circulantes nas políticas de currículo. A partir de sua investigação, encontramos determinados traços globais e locais nas releituras das definições oficiais, bem como nos efeitos dessas políticas na sociedade por intermédio da escolha de certas finalidades em detrimento de outras. Tais políticas deslizam ao longo de todo seu processo de constituição, por intermédio de ordenações discursivas e mecanismos de regulação diversos.

Segundo Hall (1997, p. 36), “o movimento em direção às 'forças libertadoras do livre mercado' e a estratégia de 'privatização' tornaram-se a força motora de estratégias econômicas e culturais tanto nacionais quanto internacionais". As políticas reformistas adotadas nas últimas décadas por diversos governos, fomentadas por organizações supranacionais financiadoras de projetos, tais como o Banco Mundial e o Fundo Monetário Internacional, por meio de seus programas de ajustes estruturais, revelam a adoção de políticas marcadamente privatizantes, de redução do financiamento estatal e a adoção da cultura do livre mercado como forma de regulação. Mas em torno dessas ações que envolvem interesses materiais bem-delineados, há a circulação de discursos globais e locais que buscam construir a legitimação de tais orientações. Comunidades epistêmicas globais e locais (ANTONIADES, 2003) são formadas difundindo e reinterpretando tais orientações.

Um exemplo desses discursos pode ser identificado no Relatório Delors (DELORS, 2001), documento produzido pela Unesco e que se propõe "afirmar a sua fé no papel essencial da educação no desenvolvimento contínuo, tanto das pessoas como das sociedades" (p. 11). Tal documento compreende a educação como uma via capaz de conduzir os países ao desenvolvimento humano, social, nacional e, por fim, global. Um dos pilares da reforma educacional, proposta nesse relatório, é a valorização de um necessário e contínuo processo de aprender a aprender, agregando ao conceito de educação um caráter contínuo e permanente a educação ao longo de toda a vida, espelhando traços de uma regularidade global nos sentidos atribuídos às finalidades da educação. Tais sentidos capilarizam-se e podem ser identificados, recontextualizados, nos projetos de políticas curriculares locais.

Em torno da ideia da eficiência e da maximização de resultados que a radicalidade do processo contínuo do aprender resulta, podemos 
assinalar a adoção de soluções de mercado visando a favorecer a emersão e o fortalecimento da cultura centrada na performatividade. O extravasamento de determinado ideário do campo da economia para outras esferas da vida social resulta, em especial no que se refere à educação, na mercantilização e na objetivação do processo de ensinaraprender e favorece sua associação à avaliação como meio de aferir o sucesso da aprendizagem. Essa tríade aprender-ensinar-avaliar apresenta cada vez mais uma relação de interdependência. Segundo Boyle (apud BALL, 2004a, p. 1116), "o ensino e a aprendizagem estão sendo reduzidos a processos de produção e de fornecimento, que devem cumprir os objetivos de mercado de transferência eficiente e de controle de qualidade".

A educação passa a ser pensada como forma de produção e serviço, sob a regência da lógica do mercado e pelo afastamento gradual do Estado em seu financiamento, mas não em sua regulação. Assim, em nome desse processo de objetivação, as especificidades dos processos educacionais que, até então, pressupunham uma necessária "interação humana”, tendem a ser prescindidas. Busca-se reduzir e subordinar a prática do ensino-aprendizagem à exterioridade, a partir da adoção de regras e da utilização de um suporte material (livros, mídia institucional, parâmetros) que se quer prescritivo, estandardizado e, por isso, mesmo passível de ser classificado, mensurado e comparado, sempre com a finalidade de se atingir metas. A mitificação política acerca da eficiência do setor privado e suas inovadoras formas de gestão propiciam a convergência do setor público em direção e de acordo com os pressupostos mercadológicas privados, tanto em seus aspectos materiais quanto nos simbólicos. Com isso, constitui-se a preocupação mais recentemente observável dentro do setor público com a gestão "das aparências, marketing e promoção" (BALL, 2004a, p. 1117).

Um dos exemplos dessa política de regulação é o surgimento de uma cultura da performatividade. Ball (2003, p. 216) define a performatividade como "uma tecnologia, uma cultura e um modo de regulação que emprega julgamentos, comparações e termina se revelando como meio de controle, de desgaste e de mudança”. Em referência ao trabalho de Lyotard, Ball (2004b, p. 142) observa dois fortes componentes que têm constituído o novo discurso de poder nas sociedades pósindustriais, quais sejam, a responsabilização (accountability) e a competição, 
a partir dos quais todo um processo de legitimação de novas identidades sociais passa a se pautar. Nesse sentido, a educação adquire ainda maior destaque, já que, por intermédio dela, busca-se, de modo mais efetivo, a transmissão da cultura da performatividade para a constituição de sujeitos mais produtivos, eficientes, polivalentes, pró-ativos, assertivos, disponíveis à compreensão de outras culturas. Instaura-se a incessante busca pelo que denominamos sujeito onicompetente, aquele que está em perene prontidão para a demonstração de seus conhecimentos e desempenhos, em constante e permanente processo de avaliação, no qual "o funcionamento do poder é garantido pelo controle constante da performatividade" (LOPES, 2004, p. 63). Para isso, as organizações lançam mão de estratégias de gestão e governança em nome de um plano de cumprimento de metas, a partir da maximização do desempenho de seus quadros e do enxugamento de custos operacionais, mesmo que em rota de colisão com questões de ordem ética, profissional, humana. Trata-se de um esforço de naturalização que a cultura da performatividade tem possibilitado, no sentido de constituir dada normatividade, o disciplinamento por intermédio de novos arranjos discursivos e de regulação social.

Há que se destacar que, em Lyotard (1986), a cultura da performatividade não é assumida como necessariamante negativa, mas como um modo diverso de legitimação do conhecimento na pós-modernidade. Para Lyotard, a ciência pós-moderna é aquela que passa a se validar pela performance, um processo de legitimação no qual o poder substitui os critérios de justiça, beleza ou verdade. Mas tal substituição não é uma mudança por julgamento de valor, mas em função do fim das metanarrativas de justificativa da ciência, sejam elas a formação do espírito ou a ideia de verdade legitimada pela prova empírica, cara ao realismo. Nesse caso, a legitimação pelo desempenho advém dos resultados que esse desempenho pode trazer para a solução de problemas, a melhoria da qualidade de vida e/ou a capacidade de produzir mais recursos econômicos.

Ainda assim, como salienta esse autor, a lógica do desempenho pode se tornar apenas uma forma de consolidação do sistema, de modo determinista, pois está prevista nessa lógica a concepção de que, a partir de determinados insumos, temos, por consequência, determinados resultados. Admitir que essa lógica existe e que com ela a ciência trabalha 
não deve significar a desconsideração de outras lógicas. É possível, como faz Lyotard, defender que a ciência também trabalha com a paralogia, forma que visa ao pluralismo cada vez maior no interior do sistema. Nesse processo, em vez de apenas se trabalhar para que melhores desempenhos sejam obtidos, seguindo as regras do jogo da ciência, busca-se romper com essas regras. Isso é possível ser feito com a identificação de paradoxos e a criação de novas regras.

A cultura da performatividade, imbuída do projeto de manutenção do sistema, entretanto, ainda que não seja a única, vem sendo disseminada privilegiadamente pela educação. Um dos exemplos que no Brasil expressa essa disseminação é o ENEM, que passamos a analisar.

\section{Avaliação e performatividade nas políticas de currículo: o caso do ENEM}

Ball (2001) analisa como essa nova economia moral, mais do que um sistema de vigilância, constrói um espetáculo que define um fluxo de performatividades contínuas e importantes. Os desempenhos dos sujeitos individuais e/ou das organizações servem como medida da produtividade e exposição pública da "qualidade". Conferir visibilidade ao conhecimento e, portanto, garantir sua medida, permanece sendo a lógica que configura os processos de avaliação, tal como em processos instrumentais instituídos em outras épocas no meio educacional (DÍAZ BARRIGA, 1992).

Tal foco na medida de desempenho pode ser percebido na avaliação das competências e habilidades. O ENEM assume, desde sua criação, a intenção de:

(...) avaliar o desempenho do aluno ao término da escolaridade básica, para aferir o desenvolvimento de competências fundamentais ao exercício pleno da cidadania (Documento Básico, p. 1). Para tal, assume a concepção de competência como modalidades estruturais da inteligência, ou melhor, ações $e$ operações que utilizamos para estabelecer relações com e entre objetos, situações, fenômenos e pessoas que desejamos conhecer. As habilidades decorrem das competências adquiridas e referem-se ao plano imediato do "saber faz̧er". Por meio das ações e operações, as habilidades aperfeiçoam-se e articulam-se, possibilitando nova reorganização das competências (aferir o desenvolvimento de competências fundamentais ao exercício pleno da cidadania) (Documento Básico, p. 5, grifos nossos). 
Como já foi discutido em outros trabalhos (LOPES, 2001; MACEDO, 2002), as competências se inserem em uma perspectiva curricular instrumental que tende a limitar o conhecimento ao saber-fazer, ao desempenho. Mesmo quando associadas às estruturas da inteligência, como no Enem, é por meio das habilidades e das performances que elas são expressas e medidas. Com isso, sua dimensão cognitiva é esvaziada de sentido, reduzindo-se a uma função de valor de troca no mercado social: afirma-se a positividade do conhecimento caso ele se expresse em um saber-fazer passível de ser trocado por vantagens sociais. Com isso, nosso questionamento não se dirige à possibilidade de que, pelo currículo, haja formação de competências e habilidades ou de que o conhecimento também seja a base de performances vinculadas a dimensões pragmáticas. A problemática se insere na redução do currículo e do conhecimento a essas dimensões. Tal processo pode se desenvolver quando a organização curricular é instituída por meio de competências e habilidades.

Uma das reinterpretações hibridizadas das competências com orientações mais críticas é a perspectiva de conhecimento situado, contextualizado, buscando sintonia com dimensões cotidianas. No caráter híbrido de tal contextualização, no entanto, também prevalecem concepções instrumentais (LOPES, 2002a), pois tende a ser valorizado o conhecimento situado em um contexto de aplicação, "sendo em parte um produto da atividade, do contexto e da cultura nas quais é desenvolvido e usado" (Informativo do Enem - Brasil, 2005a). Na medida em que as competências vão além das dimensões cognitivas, por vezes tornando nebulosas suas relações com o conhecimento, elas são igualmente pensadas no seu vínculo com os valores e as disposições do sujeito diante de situações-problema.

Busca-se, dessa maneira, verificar como o conbecimento assim construído pode ser efetivado pelo participante por meio da demonstração de sua autonomia de julgamento $e$ de ação, de atitudes, valores e procedimentos diante de situacõos-problema que se aproximem o máximo possivel das condiçoes reais de convívio social e de trabalho individual e coletivo. (Documento Básico, p. 5, grifos nossos)

É dessa forma que a concepção de conhecimento mostra-se restrita ao utilizável, ao que é situado em determinados contextos. Como discute Lyotard (1986), "o conhecimento não é mais legitimado porque é verdadeiro, porque atende princípios como ser bom, justo ou belo, mas 
porque é bem-sucedido, tem menor custo que outra opção”. O conhecimento passa a ser encarado socialmente como expressão do resultado dos exames, uma identificação não apenas construída pelos elaboradores desses exames, mas pelos que analisam seus resultados e seus efeitos sociais. É por meio da performatividade e da responsabilidade (accountability) que serviços sociais como a educação são padronizados, calculados, qualificados e comparados, em uma dinâmica na qual os conhecimentos legitimados dos estudantes passam a ser vistos como idênticos aos resultados dos testes que o representam.

A despeito de o presidente do Instituto Nacional de Pesquisas Educacionais (Inep), instituto formulador e implementador do ENEM, afirmar que a função do exame é diagnóstica para as políticas públicas e que não tem por objetivo fazer ranking de qualquer tipo de avaliação - até por saber que não só a escola, mas também a trajetória do aluno e o perfil sociocultural dele são muito importantes para os resultados obtidos (FERNANDES, 2007) -, a divulgação dos resultados de todas as escolas, por município e por ordem alfabética, permite a constituição de rankings divulgados pela mídia. $\mathrm{O}$ interesse por tais rankings gera as apressadas conclusões extraídas desses resultados, vinculando de forma imediata e simplificadora as notas dos alunos com a suposta qualidade das escolas. Mas, sobretudo, expressa o quanto a cultura da performatividade encontra sintonia com múltiplos interesses sociais, além da esfera do Estado. Tanto que, a despeito do interesse pelo tema, a discussão sobre as provas do ENEM só encontra espaço na mídia visando a ações preparatórias para os exames. É como se em uma avaliação não coubesse questionar o instrumento que gera o resultado obtido.

É importante ressaltar que a concepção de conhecimento expressa do Documento Básico do ENEM visa à integração de saberes, mostrando-se sintonizada com dimensões críticas ao currículo disciplinar e, dessa forma, construindo seu processo de legitimação junto ao meio educacional mais amplo. Como afirmado na p. 4:

(...) a concepção de conhecimento subjacente a essa matriz pressupõe colaboração, complementaridade e integração entre os conteúdos das diversas áreas do conhecimento presentes nas propostas curriculares das escolas brasileiras de ensino fundamental e médio e considera que conhecer é construir e reconstruir significados continuamente. 
$\mathrm{Na}$ medida em que a competência se expressa em um saberfazer, a integração é desenvolvida pela articulação dos diferentes saberes necessários a esse saber-fazer, assumindo, com isso, uma perspectiva instrumental, distante de outras perspectivas de integração que têm por referência os saberes dos alunos ou os saberes cotidianos (LOPES, 2008). Ou ainda, assumindo que os saberes cotidianos a serem legitimados são aqueles que permitem a inserção do indivíduo na nova lógica do mundo produtivo.

Assim, o foco nas competências e habilidades é apresentado como uma organização curricular e uma forma de avaliação obrigatórias, na medida em que são entendidas como capazes de atender às mudanças no mundo globalizado.

Esta rapidez com que as mudanças sociais se processam e alteram nossa vida cotidiana impõe um padrão mais elevado para a escolaridade básica, e o projeto pedagógico da escola deve objetivar o desenvolvimento de competências com as quais os alunos possam assimilar informações e utilizá-las em contextos adequados, interpretando códigos e linguagens e servindo-se dos conhecimentos adquiridos para a tomada de decisões autônomas e socialmente relevantes. (Documento Básico, p. 1, grifos nossos).

A suposta inexorabilidade do novo cenário naturaliza as novas formas de regulação, tornando-as mais do que obrigatórias - desejáveis -, pois buscam viabilizar a possibilidade do sucesso.

As marcas que situam o ENEM nas políticas que configuram a performatividade também podem ser identificadas nos objetivos explícitos do exame (Documento Básico, p. 2). Não se trata apenas de uma avaliação do sistema de educação básica, como prevê um dos objetivos do documento, mas é esperado que o exame sirva como referência à autoavaliação do indivíduo, "com vistas às suas escolhas futuras, tanto em relação ao mercado de trabalho quanto em relação à continuidade de estudos", bem como possibilite uma alternativa ou um complemento aos processos de seleção nos diferentes setores do mercado de trabalho e nos exames de acesso aos cursos profissionalizantes pósmédios e ao ensino superior. Tal perspectiva é corroborada pelas cartilhas do Exame (BRASIL, 2006 ${ }^{\text {; }}$ 2008) e por pesquisas desenvolvidas com candidatos do Enem (PINTO; LETICHEVSKY; GOMES, 2002)

Nesse sentido, diferencia-se de processos instrumentais de avaliação instituídos em épocas passadas, nos quais se visava à eficiência 
do sistema de ensino, tendo por base a funcionalidade do sistema social em uma base coletiva de controle. Em tempos de valorização da performatividade, o foco é o indivíduo e sua possibilidade de se autorregular por meio do autoconhecimento. Com isso, é almejada a identificação entre avaliação externa e autoavaliação, constitutivos não apenas de uma preparação para o exame, mas para a "vida". Os slogans "O ENEM prepara você para as provas da vida" (BRASIL, 2005b) e "Venha participar desta revolução" (BRASIL, 2008) buscam estabelecer essa relação com a mudança e o projeto de vida, para além de um simples processo de examinar saberes.

Com a dissolução aparente da vigilância externa - não há a obrigação de ser aprovado -, configura-se a internalização da avaliação e do exame de seu autoconhecimento. Como afirmado no Informativo do ENEM (BRASIL, 2005a, p. 18), referindo-se aos professores que prestam esse exame, "o Enem faz uma inversão necessária na pirâmide das políticas educacionais. Ao invés de agir no sistema, para que tenha resultados no indivíduo, trabalha no indivíduo e gera conseqüências no sistema". É a autorregulação das performances do indivíduo que são entendidas como base de manutenção do funcionamento do sistema.

Ainda que localizado ao final do ensino médio, o Enem tende a vincular o conhecimento, expresso nas competências e habilidades, ao que é entendido como necessário ao indivíduo em toda sua vida. É simultaneamente afirmado que o exame é voluntário, um direito do aluno, mas também uma necessidade da vida contemporânea. No slogan final do Informativo do ENEM (BRASIL, 2005a, p. 32) - "A vida é cheia de opções. Esteja pronto para escolher as melhores" -, a vinculação com a qualidade do conhecimento necessário ao mundo e ao trabalho que se transformam tão rapidamente, a instauração da incerteza quanto ao futuro e a instabilidade da avaliação constante configuram o quadro que permite à cultura da performatividade se inserir nas políticas de currículo.

Cabe destacar, ainda, que, enquanto os exames vestibulares são vistos como norteadores de conteúdos utilizados para determinar a entrada nos níveis superiores e, dessa forma, controlar os currículos do nível médio, o ENEM colocou-se, inicialmente, com uma tarefa mais profunda: estabelecer as performances exigidas para a vida e para o trabalho, dimensões que se associam e se reforçam na forma como tendem a ser entendidas na cultura global. Com isso, a perspectiva de 
controle centralizado do currículo do nível médio também se acentua (MILDNER; SILVA, 2002a), porém não mais centralizado nos conteúdos, mas nas competências e habilidades. A relativa ausência da validade de conteúdo em provas do Enem já foi evidenciada por trabalhos que analisam as questões de Química e de Língua Portuguesa (MILDNER; SILVA, 2002a; 2002b), e também pode ser constatada pela compreensão geral que os alunos de nível médio têm em relação às provas.

$\mathrm{Na}$ medida em que o exame se tornou também a possibilidade de acesso ao Programa Universidade para Todos (ProUni), a esses objetivos foi agregado, mais acentuadamente ${ }^{2}$, o de acesso ao nível superior. Nesse caso, é possível perceber, nos documentos de divulgação do exame, a superposição desse discurso regulador das competências e habilidades com o discurso que busca ampliar as possibilidades de acesso ao ensino superior. A despeito das críticas ao ProUni, em virtude do direcionamento de verbas para o sistema privado de ensino, a ele se associa uma dimensão democrática de tentativa de diminuição da desigualdade de acesso no ensino superior. Nesse caso, os efeitos de primeira ordem (BALL, 1994), vinculados à garantia da instrução, mais marcantes nas primeiras versões do Enem, são articulados aos efeitos de segunda ordem descritos pelo mesmo autor, que tentam obter resultados de ampliação da justiça social.

Dessa forma, o ENEM, como um sistema avaliativo que condensa os princípios da Reforma Educacional do Ensino Médio brasileiro, se constitui como um dispositivo que entrelaça e interpenetra o processo de ensino-aprendizagem em múltiplos níveis, já que, a partir dele, são engendrados tanto resultados globais (relativos às redes de ensino), quanto locais (referentes às unidades locais) e individuais (relativos ao aluno). Igualmente, o ENEM participa do fortalecimento e da circulação dos princípios da reforma, pois, em seu entrelaçamento e em seu processo de negociação com os múltiplos contextos com os quais se relaciona, produz efeitos mais ou menos convergentes de adesão a seus princípios. Pelos efeitos que produz nas políticas de currículo, os discursos associados a esse exame constituem um contexto de influência para outras ações curriculares e também para outros sistemas de avaliação.

Localmente, o vestibular da Universidade do Estado do Rio de Janeiro (UERJ) é um exemplo dessa influência (LÓPEZ, 2007). O pro- 
cesso de construção do novo modelo de Vestibular da UERJ, em 2000, partiu da justificativa de adequação de seu processo avaliativo às novas prerrogativas legais em curso à época, quais sejam, a nova LDB, as diretrizes e aos parâmetros curriculares para o ensino médio. Cumpre destacar, no entanto, que tal modelo emerge de um processo anterior ${ }^{3}$, mais amplo e complexo, de reestruturação do projeto universitário da instituição, que visava a criar condições para a produção de conhecimento científico e incremento à pesquisa na universidade, rompendo com sua tradição vocacional de formação profissional, até então, instituída desde sua fundação. Vinculou-se, assim, a um projeto que contribuiu não só para a modernização dessa instituição de nível superior como para ampliar as possibilidades de cumprir com finalidades sociais de pesquisa esperadas de uma universidade.

Os argumentos jurídico-normativos utilizados contribuíram para o esmaecimento de resistências internas que poderiam obstaculizar a institucionalização dessa nova agenda para a universidade. Assim, princípios observados na Reforma Educacional brasileira, tais como a integração curricular, a contextualização e a avaliação baseada na aferição de competências e habilidades, foram apropriados no escopo desse novo modelo de concurso vestibular. Na análise de López (2007), no entanto, com base na perspectiva de Stephen Ball, os sentidos das políticas, quando em seu processo de negociação entre os múltiplos contextos pelos quais transita, expressam os acordos entre as lutas pelo poder de significação das políticas educacionais. Isso resultou especificamente, no caso da UERJ, uma hibridização de sentidos que amalgama princípios da reforma e da tradição disciplinar da universidade, produzindo políticas curriculares para o ensino médio diferenciadas daquelas intencionadas pela Reforma Educacional. Seus efeitos, portanto, não podem ser traduzidos como mera extensão dos efeitos do Enem, ainda que neles se baseassem.

\section{Conclusões}

Para concluir, é importante salientar o quanto a constituição da cultura da performatividade de forma global não é um processo que verticalmente se impõe a nós, como uma dimensão externa aos sujeitos, 
mas sim uma rede de poderes nas quais nos constituímos. A existência dessa cultura não é por nós entendida como uma produção exclusiva do contexto de influência e/ou do contexto de produção de textos delineados por Ball, mas como dinâmicas que se articulam em múltiplos contextos e que também têm sua produção engendrada no contexto da prática. Assim, contam com a participação de múltiplos sujeitos capazes de construir comunidades epistêmicas globais e locais em defesa das avaliações centralizadas nos resultados e de sua associação com a qualidade da educação. Não é incomum encontrarmos escolas que, em torno do Enem, vêm construindo práticas que estimulam seus alunos aos estudos e buscam sua valorização social e o desenvolvimento de sua autoestima.

Também é possível destacar, como procuramos argumentar ao longo do texto, como a perspectiva instrumental predominante no exame encontra-se hibridizada a outras tendências, que tanto podem assumir um viés mais democrático - quando sinalizam a necessidade de diminuir a desigualdade de acesso à universidade - quanto podem acentuar os efeitos performáticos - constituindo rankings supostamente científicos de escolas.

Nessa perspectiva, existem dimensões locais das avaliações, diferentes extensões de seus efeitos a serem analisados, inclusive considerando as diferentes leituras em contextos institucionais e disciplinares diversos. Defendemos, portanto, ser necessário associar a essa análise a investigação dos sentidos e significados produzidos nas políticas pelos exames já realizados.

Mas já é possível perceber como o foco na formação do indivíduo onicompetente para a eficiência social do sistema de ensino e do sistema social, centrado na autorregulação de suas performances, tenta se tornar uma meta a ser alcançada, na construção dessa cultura da performatividade. Dessa forma, mais do que a eficiência social das perspectivas instrumentais de outras épocas, com algum sentido voltado ao coletivo, busca-se a eficiência do indivíduo autorregulado, supostamente capaz de vir a se traduzir em uma eficiência do sistema.

Tal meta não se estabelece em todos os níveis da mesma forma, tampouco é possível afirmar que ela se estabeleça de uma vez por todas. Mas a existência de esforços nessa direção já é suficiente, a nosso ver, para que busquemos estabelecer e reforçar ações no sentido de acentuar políticas sintonizadas com o caráter diagnóstico das avaliações e com a 
possibilidade de questionar o foco no desempenho quando ele só se mostra como produtor de efeitos não-democráticos. Em outras palavras, torna-se fundamental não restringir a avaliação e o currículo ao foco no desempenho. Diferentemente, mostra-se importante tornar o foco no desempenho uma forma de evidência pública vinculada à luta pela diminuição das desigualdades sociais.

Por fim, cabe destacar que tais questões nos apontam não apenas para problematizarmos o projeto e os efeitos decorrentes de uma cultura da performatividade no currículo, mas também para questionarmos esses efeitos, atuarmos no sentido de reinterpretá-los e redirecioná-los, na medida em que "em si mesmas as regras são vazias, violentas, não finalizadas; elas são feitas para servir a isto ou àquilo; elas podem ser burladas ao sabor da vontade de uns ou de outros" (FOUCAULT, 1989, p. 25).

\section{Referências}

ANTONIADES, Andreas. Epistemic communities, epistemes and the construction of (world) politics. Global society, v. 17, n. 1, p. 21-38, 2003.

BALL, Stephen J. Education reform: a critical and post-structural approach. Buckinghan: Open University, 1994.

BALL, Stephen J. Policy sociology and critical social research: a personal review of recent education policy and policy research. British educational research journal. v. 23, n. 3, p. 257-274, 1997.

BALL, Stephen J. Cidadania Global, Consumo e Política Educacional. In: SILVA, Luiz Heron (Org.) A escola cidadã no contexto da globalização. Petrópolis: Vozes, 1998, p. 121-137. BALL, Stephen J. Diretrizes Políticas globais e relações políticas locais em educação. Currículo sem Fronteiras. v. 1, n. 2, p. 99-116, dez, 2001.

BALL, Stephen J. The teacher's soul and the terrors of performativity. Journal of Education Policy. v. 18, n. 2, p. 215-228, 2003.

BALL, Stephen J. Performatividade, privatização e o pós-Estado do bem-estar. Educação e Sociedade, v. 25, n. 89, p. 1105-1126, set/dez 2004a.

BALL, Stephen J. Performativities and Fabrications in the Educational Economy: towards the performative society In: Ball, Stephen J. (ed.) The Routledeg Falmer Reader in Sociology of Education. Londres: Routledge Falmer, 2004b. p. 143-155.

DELORS, Jacques. Educação: um tesouro a descobrir. Relatório para a UNESCO da Cvomissão Internacional sobre Educação para o século XXI. São Paulo: Cortez, 2001. DIAS, Rosanne Evangelista. Profissionalização docente e a cultura da performatividade. In: Anais do XIII ENDIPE - Encontro Nacional de Didática e Prática de Ensino, Recife, 2006. DÍAZ BARRIGA, Angel. Didactica y curriculum. Mexico: Nuevomar, 1992. FOUCAULT, Michel. Microfísica do poder. Rio de Janeiro: Graal, 1989. 
HALL, Stuart. A centralidade da cultura: notas sobre as revoluções de nosso tempo. Educação \& Realidade. Porto Alegre, v. 22, n. 2, jul/dez, 1997.

JAMESON, Friederich. A cultura do dinheiro: ensaios sobre a globalização. Petrópolis, Vozes, 2002.

LINGARD, Bob. É ou não é: globalização vernacular, política e reestruturação u. In: Burbules, Nicholas C. \& Torres, Carlos Alberto. Globalização e Educação. Porto Alegre: Artes Médicas, p. 59-76, 2004.

LOPES, Alice Casimiro. Competências na organização curricular da reforma do ensino médio. Boletim Técnico do Senac, Rio de Janeiro, v. 27, n. 3, p. 1-20, 2001.

LOPES, Alice Casimiro. Os parâmetros curriculares nacionais para o ensino médio e a submissão ao mundo produtivo: o caso do conceito de contextualização. Educação \& Sociedade, São Paulo, v. 23, n. 80, p. 389-404, 2002a.

LOPES, Alice Casimiro. A organização do conhecimento escolar nos PCN para o ensino médio. In: ROSA, D. G. \& SOUZA, V. C. - XI Endipe (Org.). Políticas organizativas e curriculares, educação inclusiva e formação de professores. Rio de Janeiro: DP\&A, 2002b.

LOPES, Alice Casimiro. Políticas de Currículo: mediação por grupos disciplinares de ciências e matemática. In: Lopes, Alice Casimiro \& Macedo, Elizabeth. Currículo de Ciências em Debate. Campinas: Papirus, 2004, p. 45-76.

LOPES, Alice Casimiro. Política de currículo: recontextualização e hibridismo. Currículo sem fronteiras. V. 5, n.2, p. 50-64, jul/dez, 2005.

LOPES, Alice Casimiro. Discursos nas políticas de currículo. Currículo sem Fronteiras, v. 6, p. 33-52, 2006.

LOPES, Alice Casimiro. A articulação entre conteúdos e competências em políticas de currículo para o ensino médio. In: LOPES, Alice Casimiro; MACEDO, Elizabeth; TURA, Maria de Lourdes; LEITE, Carlinda. Politicas educativas e dinâmicas curriculares no Brasil e em Portugal. Rio de Janeiro, DPAllii, 2008. p. 189-214.

LÓPEZ, Silvia Braña. O exame na produção de políticas curriculares: a avaliação contextualizada. 166f. Dissertação (Mestrado). Universidade do Estado do Rio de Janeiro, 2007.

LYOTARD, Jean. O pós-moderno. Rio de Janeiro: José Olympio, 1986.

MACEDO, Elizabeth. Currículo e competência. In: LOPES, A. C. \& MACEDO, E. F. (Org.). Disciplinas e integração curricular: história e políticas. Rio de Janeiro: DP\&A, 2002.

MACHADO, Roberto. Introdução - por uma genealogia do poder. In: FOUCAULT, Michel. A microfísica do poder. Rio de Janeiro: Graal, 1986.

MAINARDES, Jefferson. Abordagem do ciclo de políticas: uma contribuição para a análise de políticas educacionais. Educação \& Sociedade, v. 27, n. 94, p. 47-69, jan/abr. 2006.

MILDNER, Telma; SILVA, Alexsandro da. O ENEM como forma alternativa ou complementar aos concursos vestibulares no caso das áreas de conhecimento "língua portuguesa e literatura”: relevante ou passível de refutação? Estudos em Avaliação educacional. São Paulo: n. 25, p. 43-76, jan./jun., 2002a.

MILDNER, Telma; SILVA, Leila Nascimento da. O ENEM é alternativa ao vestibular: o caso da área de Química. Avaliação - Revista da Rede de Avaliação Institucional da educação Superior. Campinas, SP, v. 7, n. 2, p. 49-79, jun, 2002b.

PINTO, Fátima Cunha F; LETICHEVSKY, Ana Carolina; GOMES, Simone Caputo. O 
Enem em Síntese: propostas teóricas e desdobramentos. Ensaio: Avaliação e Políticas Públicas em Educação. Rio Comprido. v. 11, n. 40, p. 261-282, set. 2003.

ZANCHET, Beatriz. A prática avaliativa do Exame Nacional do Ensino Médio (ENEM): pressupostos conceituais e implicações no contexto escolar. Educação Unisinos. São Leopoldo, RS, v. 6, n. 11, p. 137-154, dez. 2002.

\section{Documentos analisados}

BRASIL, Ministério da Educação, Instituto Nacional de Estudos e Pesquisas Educacionais 3/4 INEP. Documento Básico. Brasília, 2000, 12 p. Disponível em:

<http://www.inep.gov.br/basica/enem/publicacoes/>. Acessado em 8 de novembro de 2005.

BRASIL, Ministério da Educação, Instituto Nacional de Estudos e Pesquisas Educacionais 3/4 INEP. Informativo do ENEM. Brasília, 2005a, 32 p. Disponível em:

<http://www.inep.gov.br/basica/enem/publicacoes/>. Acessado em 8 de novembro de 2005.

BRASIL, Ministério da Educação, Instituto Nacional de Estudos e Pesquisas Educacionais 3/4 INEP. Revista do ENEM. 2005b.

BRASIL, Ministério da Educação, Instituto Nacional de Estudos e Pesquisas Educacionais 3/4 INEP. Cartilha do ENEM. Brasília, 2006a. 24 p.

BRASIL, Ministério da Educação, Instituto Nacional de Estudos e Pesquisas Educacionais $3 / 4$ INEP. Revista do ENEM. 2006b.

BRASIL, Ministério da Educação, Instituto Nacional de Estudos e Pesquisas Educacionais 3/4 INEP. Revista do ENEM. 2007.

BRASIL, Ministério da Educação, Instituto Nacional de Estudos e Pesquisas Educacionais 3/4 INEP. Cartilha do ENEM. Brasília, 2008. 28 p

FERNANDES, Reynaldo. Entrevista: Transparência total, informação um direito de todos. In: BRASIL, Ministério da Educação, Instituto Nacional de Estudos e Pesquisas Educacionais 3/4 INEP. Revista do ENEM. 2007, p. 6-8.

\section{Notas}

1 Uma versão reduzida deste texto foi apresentada no XIII Endipe, Recife, 2006, com o título "A performatividade nas políticas de currículo: o caso do ENEM". Este trabalho faz parte do grupo de pesquisa Currículo: sujeitos, conhecimento e cultura (www.curriculo-uerj.pro.br) e contou com financiamento do CNPq, da Faperj e da UERJ.

2 Antes do ProUni, o uso do ENEM como forma de seleção aos cursos superiores era mais restrito, dependendo da decisão de cada universidade.

3 A partir dos anos 1990, a UERJ desenvolveu toda uma política de acelerar e aprofundar seu processo de produção científica. Um dos marcos desse processo é o Programa Prociência, que visa a conceder bolsa de dedicação exclusiva com base em uma avaliação por pares da produção e da pesquisa dos professores. 
Recebido: 02/03/09

Aprovado: 14/10/09

Contato:

Universidade do Estado do Rio de Janeiro Faculdade de Educação Departamento de Estudos Aplicados ao Ensino

Rua São Francisco Xavier, 524 - $12^{\circ}$ andar Maracanã

CEP 20550-013

Rio de Janeiro/RJ 